\title{
ASSESSMENT OF PHYSICAL IMPAIRMENTS IN LEPROSY PATIENTS: A COMPARISON BETWEEN THE WORLD HEALTH ORGANIZATION (WHO) DISABILITY GRADE AND THE EYE-HAND-FOOT SCORE
}

Marcos Túlio RAPOSO(1), Ana Virgínia de Queiroz CAMINHA(1), Jorg HEUKELBACH(2), Miguel Ángel SÁNCHEZ-GONZÁLEZ(3), Jovany Luis Alves de MEDEIROS(4) \& Maria Ines Battistella NEMES (5)

\begin{abstract}
SUMMARY
This cross-sectional study assessed the grade of physical impairments in 61 individuals with leprosy receiving multidrug therapy (MDT) under the Brazilian Unified Health System (SUS), and residing in Campina Grande, Paraíba State, Brazil. Impairments were assessed using the disability grade (DG) standardized by the WHO, and the EHF score (Eye-Hand-Foot sum of impairment scores). Impairments were detected in $25(41 \%)$ of the subjects. A total of $14(23 \%)$ patients scored DG 1, while $11(18 \%)$ were assigned DG 2. The EHF score ranged from 1 to 10 points in the group of patients with physical impairments, with a mean score of 3.6 points. The majority of individuals with impairments were affected in at least two sites. We conclude that the EHF score showed overlapping impairments in the segments examined and may be more appropriate than the DG classification system for describing the degree of physical impairment of leprosy patients.
\end{abstract}

KEYWORDS: Leprosy; Disability evaluation; Disabled health.

\section{INTRODUCTION}

The data available on physical impairments resulting from leprosy varies considerably, although the World Health Organization (WHO) estimates indicate that approximately $25 \%$ of those with leprosy have impairments ${ }^{38}$. In 2004, an estimated two to three million people were disabled by leprosy worldwide ${ }^{37}$. Trends in prevalence and case detection vary from country to country. The prevalence of people with DG 2 decreases much slower than leprosy incidence and case detection. In 2020 it is estimated that about one million people will be affected by leprosy and living with disability grading $2^{18}$.

Studies carried out in Brazil have shown that coverage of new cases assessed for disability was on average $88 \%$ in $2008^{32}$. The percentage of patients presenting grades 1 and 2 of disability were, respectively, $5.7 \%$ and $18.1 \%$ amongst 43,642 new cases of leprosy in $2006^{4}$. The proportion of DG 2 among new cases varies widely between different regions of the world and reaches rates from $1 \%$ to $21 \%{ }^{35}$.

Other Brazilian studies on the prevalence of impairments at diagnosis have reported $7.7 \%$ up to $47.8 \% \%^{8,14,15,16,17,21,31}$, while international research in Nigeria ${ }^{22}$ and Ethiopia ${ }^{25}$ found rates of $19 \%$ and $55 \%$, respectively. However, government data from both African countries only report DG 2. In Larkana-Pakistan, deformities and disabilities were noted in 55\% of $\operatorname{cases}^{27}$.
In 1960, the WHO recommended the use of a scale to classify physical impairments in individuals with leprosy, namely the "disability grading" $(\mathrm{DG})^{2,3,41}$. Working versions of the scale ${ }^{3}$ were later proposed ${ }^{39,40}$ and the version in use today was recommended by the WHO in $1997^{38}$. Another study recommends that the "WHO Disability Grading" (DG) be renamed as the "WHO Impairment Grading" (IG) to address the new perspective that the International Classification of Functioning, Disability and Health (ICF) suggested ${ }^{20}$. Under this scale, grades are attributed to each eye, hand and foot, where the highest value attributed to these points represents the "maximum disability grade" of the individual and is used as an indicator of the severity of impairment ${ }^{39}$. The scale currently adopted by the WHO is simplified into three grades ${ }^{3,37}$ (DG 0 - no disability caused by leprosy in eyes, hands and feet. DG 1 - Eye problem caused by leprosy, but vision is not severely affected (equals $6 / 60$ or better; fingers can be counted at six meters apart); loss of sensibility in hands or feet (not feeling $2 \mathrm{~g}$ mononofil). DG 2 - Eyes: lagophthalmos and/or ectropion; trichiasis; visual impairment (fingers not counted at $6 \mathrm{~m}$ ). Hands and feet: with visible damage i.e. claw hands, foot drop, reabsorption of fingers or toes, wounds $)^{38}$. Today, the DG is employed as an epidemiological indicator to assess leprosy programmes, determine early/late diagnosis ${ }^{33,36}$ and monitor patient follow-up in the health care centre over the course of treatment ${ }^{4,36}$.

The vast majority of impairments occur due to failures of the leprosy programmes in terms of rapid diagnosis and treatment. Since most 


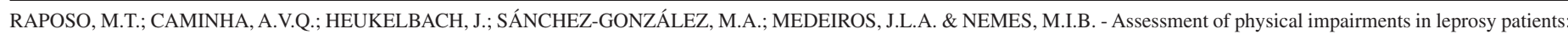
a comparison between the World Health Organization (WHO) disability grade and the Eye-Hand-Foot score. Rev. Inst. Med. Trop. Sao Paulo, 53(2): 77-81, 2011.

impairments only develop late in the course of the disease ${ }^{9}$, presence of DG 2 at diagnosis indicates late diagnosis ${ }^{28}$.

In 1971, a method was proposed to evaluate three different types of Disability Index to describe physical disabilities at the time of the diagnosis. This method had considered disability grade index achieved from the arithmetic mean of the added values of the different disability grades $^{1}$. It is important to note that the WHO disability grade was considered the best method for evaluating physical disabilities at the time of the diagnosis if compared to the absolute disabilities frequency and disability grade ${ }^{29}$.

An alternative scale called the Hand-Foot impairment score (HF impairment score $)^{12}$, was proposed in 1994 and employs the sum of impairment grades in hands and feet to monitor physical impairments in patients during the course of multidrug therapy (MDT) and over a five-year period after cure.

Previous studies ${ }^{6,10,19,24,30}$ have also employed the Eye-Hand-Foot impairment score (EHF score), which uses the sum of impairment grades assigned individually to each segment examined and encompasses eyes as well as hands and feet, yielding a total score which ranges from 0 (zero) to a maximum of 12 points. The EHF tool is an indicator of severity and development of impairment and allows changes in the stages of impairment to be monitored in individuals or groups. Grades should be recorded at least twice, at diagnosis and again at release from treatment ${ }^{30}$.

Few studies have compared the two systems of impairment assessment ${ }^{13,19,30}$, and no such studies have yet been conducted, in Northeastern Brazil, concerning disability evaluation using EHF-score versus WHO disability grading. Given the possible applicability of the EHF score as a tool for assessing impairment within leprosy programmes, several authors have pointed to the need for further studies evaluating its performance and validity ${ }^{6,19,30}$. This study sought to analyze the extent of impairment in leprosy patients based on the system of disability grading (DG) as well as the sum of the Eye-Hand-Foot impairment score (EHF score).

\section{MATERIAL AND METHODS}

Campina Grande is located in Paraíba State, Northeastern Brazil. In 2005 it had an estimated population of 376,132 inhabitants ${ }^{11}$. In 2004 145 new cases of leprosy ${ }^{26}$ were diagnosed. A cross-sectional study was carried out in a sample comprising 61 volunteers with leprosy who were invited to take part in the study.

The study was conducted from November 2003 to January 2005.
The inclusion criteria were: residence in the municipality of Campina Grande-Paraíba State-Brazil, receiving public health-care assistance under the Brazilian Unified Health System (SUS), and taking MDT for active leprosy, irrespective of gender, clinical form or age. Six patients who presented any associated health problems whose sequelae could affect the peripheral nervous system or result in similar impairments to those of leprosy were excluded. Two subjects refused to participate.

Patients were examined at the health service or their homes. The impairments were measured using the DG - the tool standardized by the $\mathrm{WHO}^{38}$, and by the EHF score - Eye-Hand-Foot impairment score ${ }^{30}$.

To exclude inter-observer variation, all physical-functional assessments were conducted by a single experienced investigator (M.T.R.).

The data were analyzed using the Epi Info ${ }^{\mathrm{TM}}$ software version 3.3, with distribution of frequencies and averages, applying the MannWhitney test with a significance level of $5 \%$.

The project was approved by the Research Ethics Committee of the State University of Paraíba, under number 164/03. All participants, or their respective legal guardians, signed the informed written consent term.

\section{RESULTS}

We included 61 patients, $32(52.5 \%)$ females and 29 (47.5\%) males. The mean age was 41 years and median 43 years (range: $8-85$ years).

Based on the working classification (leprosy group) $)^{38}, 26$ cases $(42.6 \%)$ showed paucibacillary leprosy (PB) and $35(57.4 \%)$ with multibacillary leprosy (MB).

A total of $25(41 \%)$ leprosy patients showed impairments. Assessment of impairment using the DG scale, classified 36 of the subjects as DG $0(59 \%), 14(23 \%)$ patients as DG 1 and 11 (18\%) as DG 2. Among impairment patients, EHF scores ranged from 1 to 10 points (Table 1).

Table 2 shows a higher mean EHF score count in the DG 2 patient subgroup than the DG 1 patient subgroup.

Of the patients classified as DG 1, $10(71.4 \%)$ had up to two segments involved, whereas of those assigned DG 2, 8 (72.7\%) had three or more impaired segments.

Of the 25 patients with impairments, 13 (52\%) had an EHF score of 1 to 2 and impairments in up to two segments. Among those with EHF

Table 1

Number of patients with impairment by WHO DG and EHF score $(n=25)$

\begin{tabular}{|c|c|c|c|c|c|c|c|c|c|c|c|c|c|}
\hline \multirow{2}{*}{ WHO disability grading } & \multicolumn{13}{|c|}{ EHF Score } \\
\hline & 1 & 2 & 3 & 4 & 5 & 6 & 7 & 8 & 9 & 10 & 11 & 12 & Total \\
\hline Grade 1 & 2 & 8 & 2 & 2 & - & - & - & - & - & - & - & - & 14 \\
\hline Grade 2 & - & 3 & - & - & 3 & 2 & 1 & 1 & - & 1 & - & - & 11 \\
\hline Total & 2 & 11 & 2 & 2 & 3 & 2 & 1 & 1 & - & 1 & - & - & 25 \\
\hline
\end{tabular}




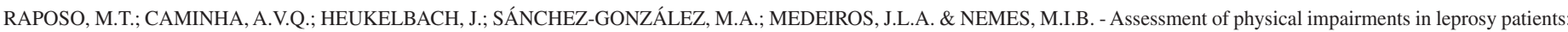
a comparison between the World Health Organization (WHO) disability grade and the Eye-Hand-Foot score. Rev. Inst. Med. Trop. Sao Paulo, 53(2): 77-81, 2011.

Table 2

Mean (SD), median EHF score by IG 1 and IG 2 subgroups.

\begin{tabular}{lcc}
\hline WHO disability & \multicolumn{2}{c}{ EHF Score } \\
\cline { 2 - 3 } grading & Mean and Standard Deviation & Median \\
\hline DG 1 $(\mathbf{n}=\mathbf{1 4})$ & $2.28 \pm 0.91$ & $2 *$ \\
DG 2 $(\mathbf{n}=\mathbf{1 1})$ & $5.27 \pm 2.57$ & 5 \\
\hline Total $(\mathbf{n}=\mathbf{2 5})$ & $3.6 \pm 2.34$ & 2 \\
\hline
\end{tabular}

* Mann-Whitney, $U: 9.227, p=0.0024$

scores greater than or equal to 3 , nine $(36 \%)$ had more than four affected segments (Table 3 ).

\section{DISCUSSION}

Given that both methods of measuring impairment combine impairments of different severities and sites into a single measure, they are concordant as severity increases, i.e. the greater the DG, the greater the EHF score. Consequently, the mean EHF total score in the DG 2 patient subgroup was greater than in the DG 1 patient subgroup. Similar to data from MEIMA et al. ${ }^{19}$, all patients with EHF scores greater than or equal to five were found to have involvement of at least one extremity or eye with DG 2.

The overlapping of impairments in the same individual, although occurring in both methods, seemed more evident in the scale of the EHF score. In the present study, while the DG predominantly classified patients with impairments in up to four segments as DG 1, the EHF score for the same group ranged from 1 to 8 . Similarly, the DG classified patients with one to six impaired segments as grade 2, where the same group scored between 3 and 10 points on the EHF scale.

This is the case because the EHF score accounts for alteration in different areas and therefore provides more in-depth information on the degree of impairments in a given individual, a finding previously reported in an earlier study ${ }^{7}$.

The greater detail offered by the EHF score makes it more suited for assessing development of impairments over the course of treatment. Moreover, previous studies have pointed to higher sensitivity of the EHF score for registering changes in impairment than the maximum WHO disability grade gr, $^{6,30}$.

A limitation attributed to the EHF score is that a change in impairment can be "masked" if variations in grades assigned to different components occur in opposite directions, thereby canceling each other out while leaving total score unchanged ${ }^{28,30}$. However, this phenomenon may also occur when using the maximum WHO disability $\operatorname{grade}^{30}$. In a cohort study following 433 patients during treatment, the masking effect on EHF scores was a rare occurrence ${ }^{19}$.

A study investigating inter-observer reliability showed the EHF score to be slightly better than the $\mathrm{DG}^{20}$. Nevertheless, in light of the similar reliability of both methods, the author advocated the use of the DG by virtue of its simplicity and ease of application.

However, the EHF score is merely the sum of the highest grades of impairment in each segment, and therefore the clinical methodology of assessing impairments is the same under both methods, the only difference being in the way impairments are classified. The simplicity of the 3-level DG scale is, though, more favorable as it enables simplifying records and monitoring systems. Nonetheless, from a clinical standpoint and for the purposes of monitoring patient conditions over the long term, the total sum of impairments of the EHF conveys more precise information than the conventional $\mathrm{DG}^{12,30}$.

This study presents some limitations related to the number of participants and individuals with impairments by leprosy. Therefore, the findings cannot be generalized. Despite these limitations, this study revealed that the elevated prevalence of impairment is in agreement with some data in the leprosy literature ${ }^{8,21,25,27}$. These findings suggest a delay in the diagnosis as an indicator of the operational difficulties of the programme ${ }^{23,28,33,36}$; highlight the need for monitoring of these subjects after treatment completion; organizing and developing activities related to the leprosy control activities carried out by Primary Health Care Services

\section{CONCLUSIONS}

The EHF score ranged from 1 to 10 points in the patient group with impairments, giving a mean score of 3.6 and median of 2 points. The majority of individuals presenting impairments were affected in at least

Table 3

Number of affected sites in cases with impairments by DG and EHF score $(\mathrm{n}=25)$.

\begin{tabular}{|c|c|c|c|c|c|c|c|c|c|c|c|c|c|c|c|c|}
\hline \multirow{2}{*}{ Sites (n) } & \multicolumn{3}{|c|}{ WHO DG } & \multicolumn{13}{|c|}{ EHF Score } \\
\hline & 1 & 2 & Total & 1 & 2 & 3 & 4 & 5 & 6 & 7 & 8 & 9 & 10 & 11 & 12 & Total \\
\hline 1 Site. & 2 & 3 & 5 & 2 & 3 & - & - & - & - & - & - & - & - & - & - & 5 \\
\hline 2 Sites. & 8 & - & 8 & - & 8 & - & - & - & - & - & - & - & - & - & - & 8 \\
\hline 3 Sites. & 2 & 1 & 3 & - & - & 2 & - & 1 & - & - & - & - & - & - & - & 3 \\
\hline 4 Sites. & 2 & 4 & 6 & - & - & - & 2 & 2 & 1 & - & 1 & - & - & - & - & 6 \\
\hline 5 Sites. & - & 2 & 2 & - & - & - & - & - & 1 & 1 & - & - & - & - & - & 2 \\
\hline 6 Sites. & - & 1 & 1 & - & - & - & - & - & - & - & - & - & 1 & - & - & 1 \\
\hline Total & 14 & 11 & 25 & 2 & 11 & 2 & 2 & 3 & 2 & 1 & 1 & - & 1 & - & - & 25 \\
\hline
\end{tabular}


RAPOSO, M.T.; CAMINHA, A.V.Q.; HEUKELBACH, J.; SÁNCHEZ-GONZÁLEZ, M.A.; MEDEIROS, J.L.A. \& NEMES, M.I.B. - Assessment of physical impairments in leprosy patients: a comparison between the World Health Organization (WHO) disability grade and the Eye-Hand-Foot score. Rev. Inst. Med. Trop. Sao Paulo, 53(2): 77-81, 2011.

two sites. EHF score showed overlapping impairments in the segments examined and proved more suited than the DG classification system for describing the degree of physical impairment of patients.

Our findings corroborate the use of the EHF score for follow-up of patients with impairments, and suggest that the term "Escore OMP - Escore Olhos, Mãos e Pés" (Eye-hand-foot Score) should be adopted by the Leprosy Control Programme in Brazil.

\section{RESUMO}

\section{Avaliação de incapacidades físicas em pessoas com hanseníase: comparação entre o grau de incapacidade e o Eye-Hand-Foot Score}

Este estudo transversal avaliou a extensão das incapacidades físicas em 61 pessoas com hanseníase, em uso de poliquimioterapia (PQT), assistidos pelo Sistema Único de Saúde do Brasil, residentes em Campina Grande, Paraíba, Brasil. As incapacidades foram avaliadas por meio do grau de incapacidade (GI) preconizado pela OMS e pelo cálculo da soma das incapacidades - Eye-Hand-Foot impairment score (EHF score); incapacidades foram diagnosticadas em $41 \%$ dos sujeitos. Os GI 1 e 2 foram atribuídos, respectivamente, para $23 \%$ e $18 \%$ deles. No grupo de pacientes com incapacidades físicas o EHF score variou de 1 a 10 pontos e exibiu a média igual a 3,6 pontos. A maioria das pessoas com incapacidades possuía, pelo menos, duas partes do corpo afetadas. $O E H F$ score evidenciou sobreposição de comprometimentos nos segmentos examinados e se mostrou mais apropriado que o sistema de classificação do GI para descrever a extensão das incapacidades físicas dos pacientes.

\section{ACKNOWLEDGEMENTS}

The authors are thankful for the suggestions of Priscila Leiko Fuzikawa, Maria de Jesus Freitas de Alencar and Paulo Roberto Antunes de Mello Affonso. They are also grateful to Duane C. Hinders who reviewed a draft of the manuscript.

\section{AUTHORS' CONTRIBUTIONS}

Raposo MT coordinated the conception, design, acquisition, analysis and interpretation of data and, writing of the final manuscript.

Caminha AVQ contributed to design, acquisition, analysis and interpretation of data and has been involved in drafting the manuscript.

Medeiros JLA contributed to design, analysis and interpretation of data and has been involved in drafting the manuscript.

Heukelbach J and Sánchez-González MA have been involved in drafting the manuscript.

Nemes MIB contributed to analysis and interpretation of data and has been involved in drafting the manuscript.

\section{FUNDING}

The authors declare independence from funders.

\section{REFERENCES}

1. Bechelli LM, Martinez-Dominguez V. Disability index for leprosy patients. Bull World Health Organ. 1971;44:709-13.
2. Brandsma W, Larsen M, Richard C, Ebenezer M. Inter-rater reliability of WHO 'disability' grading. Lepr Rev. 2004;75:131-4

3. Brandsma WJ, van Brakel WH. WHO disability grading: operational definitions. Lepr Rev. 2003;74:366-73.

4. Brasil. Ministério da Saúde. Secretaria de Vigilância em Saúde. Departamento de Vigilância Epidemiológica. Programa Nacional de Controle da Hanseníase. Vigilância em Saúde: situação epidemiológica da hanseníase no Brasil, 2008. Brasília: Ministério da Saúde; 2008.

5. Brasil. Ministério da Saúde. Secretaria de Políticas de Saúde. Departamento de Atenção Básica. Área Técnica de Dermatologia Sanitária. Manual de prevenção de incapacidades. Brasília: Ministério da Saúde; 2001.

6. Broekhuis SM, Meima A, Koelewijn LF, Richardus JH, Benbow C, Saunderson $\mathrm{PR}$. The hand-foot impairment store as a tool for evaluating prevention of disability activities in leprosy: an exploration in patients treated with corticosteroids. Lepr Rev. 2000;71:344-54

7. Budding H, Idle G. Gradding impairment in leprosy. Lepr Rev. 2000;71:85-8.

8. Costa ALF. Hanseníase: incapacidades físicas após PQT, no período de 1994 a 1998 em Teresina-Piauí. In: $16^{\text {th }}$ International Leprosy Congress; 2002; Salvador, Brasil. Salvador: WHO; 2002 .

9. Costa IMC, Patrus AO. Incapacidades físicas em pacientes de hanseníase na faixa de zero a 14 anos, no Distrito Federal, no período de 1979 a 1989. An Bras Dermato (Rio J). 1992;67:245-9.

10. Croft RP, Nicholls PG, Richardus JH, Smith WCS. The treatment of acute nerve function impairment in leprosy: results from a prospective cohort study in Bangladesh. Lepr Rev. 2000;71:154-68.

11. DATASUS. Available from: http://tabnet.datasus.gov.br/cgi/tabcgi.exe?ibge/cnv/ poptPB.def. Accessed: August 08, 2010.

12. De Rijk AJ, Gabre S, Byass P, Berhanu T. Field evaluation of WHO-MDT of fixed duration, at ALERT, Ethiopia: the AMFES project-I. MDT course completion, caseholding and another score for disability grading. Lepr Rev. 1994;65:305-19.

13. Ebenso J, Ebenso B. Monitoring impairment in leprosy: choosing the appropriate tool. Lepr Rev. 2007; 78:270-80

14. Ferreira MLLT, Pontes MAA, Silveira MIS, Araújo LF, Kerr LRS. A demanda de um centro de referência nacional para hanseníase no nordeste brasileiro: por que o excesso de pacientes? Cad Saúde Colet (Rio J). 2008;16:243-56.

15. Ferreira J, Mengue SS, Wagner MB, Duncan BB. Estimating hidden prevalence in Hansen's disease through diagnosis delay and grade of disability at time of diagnosis. Int J Lepr Other Mycobact Dis. 2000;68:464-73.

16. Goulart ISMB, Dias CM, Oliveira ACS, Silva AA, Alves RR, Quaresemin CR, et al. Grau de incapacidade: indicador de prevalência oculta e qualidade do programa de controle da hanseníase em um centro de saúde escola no município de Uberlândia, MG. Hansen Int. 2002;27:5-13.

17. Lana FCF, Melendez JGV, Branco AC, Teixeira S, Malaquias LCC, Oliveira VAC et al. Transmissão e controle da hanseníase no município de Governador Valadares/ MG - Período 1990/2000. Hansen Int. 2002;27:83-92.

18. Meima A, van Veen NH, Richardus JH. Future prevalence of WHO grade 2 impairmen in relation to incidence trends in leprosy: an exploration. Trop Med Int Health. 2008;13:241-6.

19. Meima A, Saunderson PR, Gebre S, Desta K, Habbema JDF. Dynamics of impairment during and after treatment: the AMFES cohort. Lepr Rev. 2001;72:158-70.

20. Nienhuis WA, van Brakel WH, Butlin CR, van der Werf TS. Measuring impairmen caused by leprosy: inter-tester reliability of the WHO disability grading system. Lepr Rev. 2004:75:221-32. 


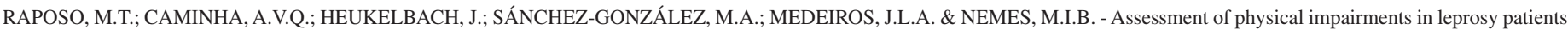
a comparison between the World Health Organization (WHO) disability grade and the Eye-Hand-Foot score. Rev. Inst. Med. Trop. Sao Paulo, 53(2): 77-81, 2011.

21. Oliveira SN, Hennemann GV, Ferreira FLF, Azevedo SA, Forster AC. Avaliação epidemiológica da hanseníase e dos serviços responsáveis por seu atendimento em Ribeirão Preto-SP no ano de1992. Medicina (Ribeirão Preto) 1996;29:114-22.

22. Peters EJ, Ansa VO, Imananagha KK, Antia EA. Time of presentation for treatment and profile of deformities among leprosy patients in South Eastern Nigeria. West Afr J Med. 2001;20:237-41

23. Raposo MT, Raposo AVC, Sánchez-González MA, Medeiros, JLA, Nemes MIB Avaliação de incapacidades em pessoas vivendo com hanseníase: análise do grau de incapacidade em Campina Grande, Paraíba. Cad Saude Colet (Rio J). 2009;17:221-33.

24. Reed NK, van Brakel WH, Reed DS. Progress of impairment scores following commencement of chemotherapy in multibacillary leprosy patients. Int J Lepr Other Mycobact Dis. 1997;65:328-36.

25. Sauderson, P. The epidemiology of reactions and nerve damage. Lepr Rev. 2000;71(Suppl):S106-10

26. Secretaria Municipal de Saúde de Campina Grande. Coordenação de Vigilância Epidemiológica. Relatório técnico. Epidemiologia da hanseníase. Campina Grande: 2005.

27. Soomro FR, Pathan GM, Abbasi P, Bhatti S, Hussain J, Yoshihisahashiguchi. Deformity and disability index in patients of leprosy in Larkana region. J Pak Assoc Dermatol (Lahore). 2008;18:29-32.

28. The International Federation of Anti-Leprosy Association. The interpretation of epidemiological indicators in leprosy. London: ILEP; 2001. (Technical Bulletin).

29. Trindade MAB, Lima FD, Almeida RG. Incapacidades físicas em hanseníase no momento do diagnóstico. I - Avaliação das incapacidades. Hansen Int. 1987;12:21-8.

30. van Brakel WH, Reed NK, Reed DS. Grading impairment in leprosy. Lepr Rev. 1999;70:180-8.

31. Vásquez FG, Parente RCP, Pedrosa LV. Hansen's disease in Coari: epidemiological aspects of the disease in middle Solimões river, state of Amazonas. Cad Saúde Colet (Rio J). 2008;16:193-204
32. World Health Organization. Monitoring grade-2 disability rate and applicability of chemoprophylaxis in leprosy control: Report of the Informal Consultation. Geneva: WHO; 2010.

33. World Health Organization. Enhanced global strategy for further reducing the disease burden due to leprosy. Nova Delhi: WHO; 2009.

34. World Health Organization. Global leprosy situation, 2007. Wkly Epidemiol Rec (Geneva). 2007;82:225-32

35. World Health Organization. Global leprosy situation. Wkly Epidemiol Rec (Geneva) 2006;81:309-16

36. World Health Organization. Global strategy for further reducing the leprosy burden and sustaining leprosy control activities (plan period: 2006-2010). Geneva: WHO 2005

37. World Health Organization. WHO Leprosy Elimanation Project. Status Report 2003 Geneva: WHO; 2004.

38. World Health Organization. WHO Expert Committee on Leprosy. Seventh Report Geneva: WHO; 1998. (WHO Technical Report Series; 874).

39. World Health Organization. WHO Expert Committee on Leprosy. Sixth Report Geneva: WHO; 1988. (WHO Technical Report Series; 768)

40. World Health Organization. WHO Expert Committee on Leprosy. Fourth Report Geneva: WHO; 1970. (WHO Technical Report Series; 459).

41. World Health Organization. WHO Expert Committee on Leprosy. Second Report Geneva: WHO; 1960. (WHO Technical Report Series; 189).

Received: 6 May 2010

Accepted: 10 January 2011 


\section{Revista do Instituto de Medicina Tropical de São Paulo on line.}

Publications from 1990 to the present data are now available on:

http://www.scielo.br/rimtsp

PAST ISSUES 1959-1989 (PDF)

www.imt.usp.br/portal/

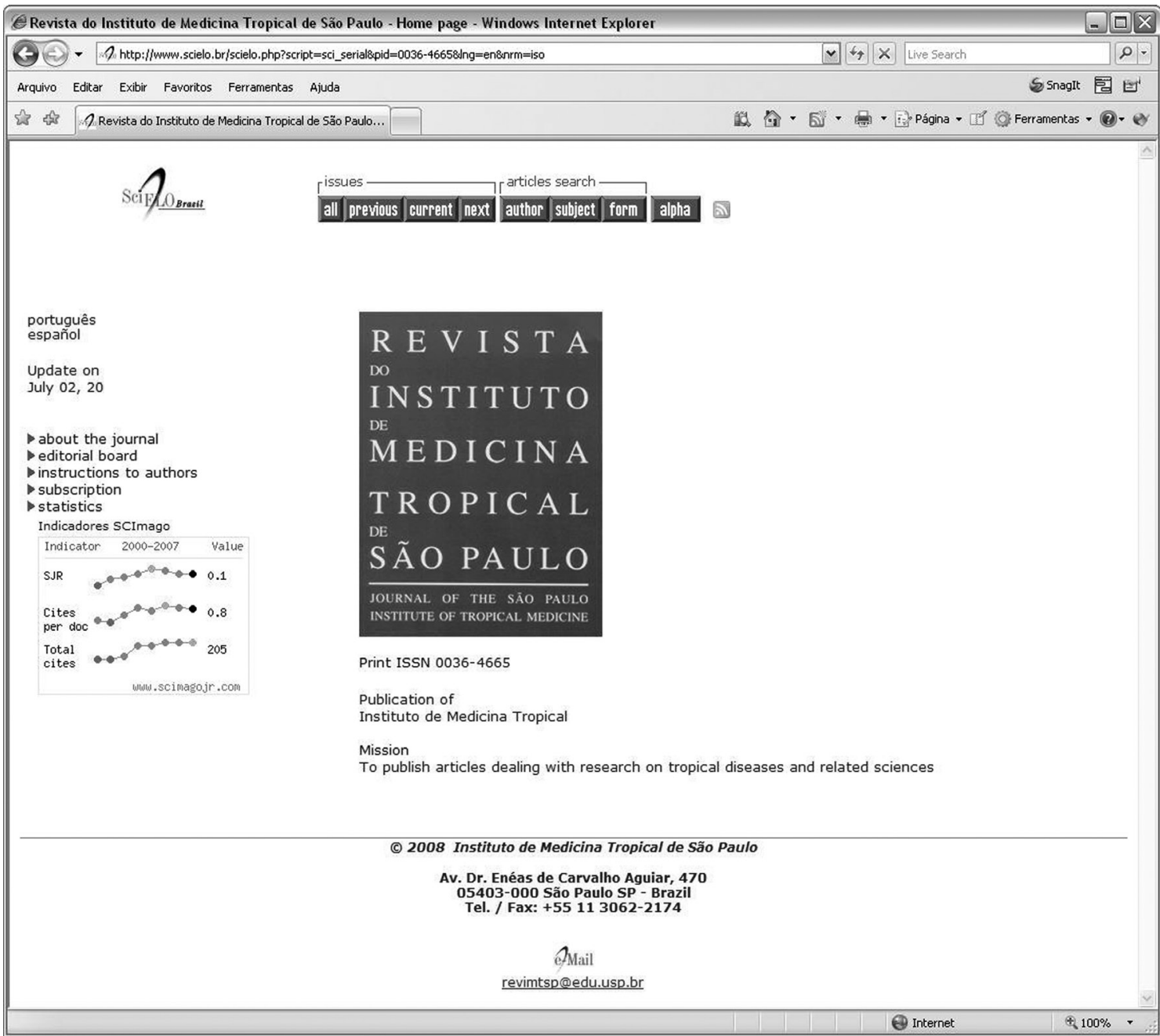

SciELO - The Scientific Electronic Library OnLine - SciELO is an electronic virtual covering a selected collection of Brazilian scientific journals.

The library is an integral part of a project being developed by FAPESP - Fundação de Amparo à Pesquisa do Estado de São Paulo, in partnership with BIREME - the Latin American and Caribbean Center on Health Sciences Information.

SciELO interface provides access to its serials collection via an alphabetic list of titles or a subject index or a search by word of serial titles, publisher names, city of publication and subject.

The interface also provides access to the full text of articles via author index or subject index or a search form on article elements such as author names, words from title, subject and words from full text.

FAPESP/BIREME Project on Scientific Electronic Publications Latin American and Caribbean Center on Health Sciences Information

Rua Botucatu 862 - 04023-901 São Paulo, SP - Brazil

Tel. (011) 5576-9863

scielo@bireme.br 